\title{
Synthesized Heparan Sulfate Competitors Attenuate Pseudomonas aeruginosa Lung Infection
}

\author{
Nicola Ivan Lorè ${ }^{1,2, *, \dagger}$, Noemi Veraldi ${ }^{3, \dagger}$, Camilla Riva ${ }^{1}$, Barbara Sipione ${ }^{1}$, \\ Lorenza Spagnuolo $^{1}$, Ida De Fino ${ }^{1}$, Medede Melessike ${ }^{1}$, Elisa Calzi ${ }^{3}$, \\ Alessandra Bragonzi ${ }^{1}$, Annamaria Naggi ${ }^{3}$ (D) and Cristina Cigana ${ }^{1, *}$ \\ 1 Division of Immunology, Transplantation and Infectious Diseases, IRCCS San Raffaele Scientific Institute, Milano \\ 20132, Italy; riva.camilla@hsr.it (C.R.); sipione.barbara@hsr.it (B.S.); lorenza.spagnuolo@quintilesims.com (L.S.); \\ defino.ida@hsr.it (I.D.F.); melessike.medede@hsr.it (M.M.); bragonzi.alessandra@hsr.it (A.B.) \\ 2 Vita-Salute San Raffaele University, Milano 20132, Italy \\ 3 Istituto di Ricerche Chimiche e Biochimiche “G. Ronzoni”, Milano 20133, Italy; \\ noemi.veraldi@gmail.com (N.V.); elisacalzi@libero.it (E.C.); naggi@ronzoni.it (A.N.) \\ * Correspondence: lore.nicolaivan@hsr.it (N.I.L.); cigana.cristina@hsr.it (C.C.); \\ Tel.: +39-02-2643-9121 (N.I.L. \& C.C.) \\ + These authors contributed equally to this work.
}

Received: 30 November 2017; Accepted: 5 January 2018; Published: 9 January 2018

\begin{abstract}
Several chronic respiratory diseases are characterized by recurrent and/or persistent infections, chronic inflammatory responses and tissue remodeling, including increased levels of glycosaminoglycans which are known structural components of the airways. Among glycosaminoglycans, heparan sulfate (HS) has been suggested to contribute to excessive inflammatory responses. Here, we aim at (i) investigating whether long-term infection by Pseudomonas aeruginosa, one of the most worrisome threat in chronic respiratory diseases, may impact HS levels, and (ii) exploring HS competitors as potential anti-inflammatory drugs during P. aeruginosa pneumonia. P. aeruginosa clinical strains and ad-hoc synthesized HS competitors were used in vitro and in murine models of lung infection. During long-term chronic P. aeruginosa colonization, infected mice showed higher heparin/HS levels, evaluated by high performance liquid chromatography-mass spectrometry after selective enzymatic digestion, compared to uninfected mice. Among HS competitors, an $\mathrm{N}$-acetyl heparin and a glycol-split heparin dampened leukocyte recruitment and cytokine/chemokine production induced by acute and chronic P. aeruginosa pneumonia in mice. Furthermore, treatment with HS competitors reduced bacterial burden during chronic murine lung infection. In vitro, P. aeruginosa biofilm formation decreased upon treatment with HS competitors. Overall, these findings support further evaluation of HS competitors as a novel therapy to counteract inflammation and infection during P. aeruginosa pneumonia.
\end{abstract}

Keywords: Pseudomonas aeruginosa infections; glycosaminoglycans; anti-inflammatory drugs; mouse models; chronic respiratory diseases

\section{Introduction}

Chronic respiratory diseases with different etiology, such as cystic fibrosis (CF), non-CF bronchiectasis, idiopathic pulmonary fibrosis (IPF) and advanced chronic obstructive pulmonary disease (COPD) show common traits such as recurrent and/or persistent infections, together with chronic inflammatory responses and immunopathology [1-3]. In particular, Pseudomonas aeruginosa infections are associated with an exaggerated inflammatory response, including neutrophil recruitment, and excessive tissue remodeling. The pathophysiological mechanisms underlying this 
immunopathological scenario in response to P. aeruginosa infections during chronic airway diseases remain to be deciphered.

The lung extracellular matrix represents a highly dynamic complex of fibrous proteins, glycoproteins, and proteoglycans, that composes the non-cellular aspect of tissues and varies in composition according to pathophysiological circumstances. In this context, glycosaminoglycans (GAGs) are long, linear, and heterogeneous polysaccharides formed by repetition of disaccharide units, that not only represent principal components of the extracellular matrix, but are also distributed in the subepithelial tissue, bronchial walls and airway secretions [4]. They include hyaluronic acid, dermatan sulfate (DS), keratan sulfate, heparin and chondroitin sulfate (CS), but the most abundant in the lung parenchyma is heparan sulfate (HS). HS binds several effector molecules, known to be involved in chronic respiratory disease such as COPD and CF. For example, the binding of chemokines to GAGs is thought to favor the generation of the chemotactic gradient [5] responsible for leukocyte recruitment to the site of infection/injury. In addition, HS can bind cytokines and chemokines, such as interferon-(IFN-) $\gamma$ and interleukin-(IL-)8, protecting them from proteolytic degradation and, thus, increasing their activities [6,7]. Therefore, high neutrophil recruitment in the airways of patients with chronic respiratory diseases may be due not only to increased chemokines expression, but also to their increased stability and prolonged activity when they are bound to HS. This pathological scenario would finally include also tissue remodeling and fibrosis.

Reports indicate that not only the amounts, but also sulfation of GAGs are markedly increased in CF tissues. Secretion of HS is elevated in CF airways, potentially correlating with the exaggerated inflammatory response described in the CF lung [7]. HS levels are increased also in the bronchoalveolar lavage fluid (BALF) of COPD patients with bacterial infections and during exacerbations [8]. In addition, high levels and sulfation of HS have been described also in patients with IPF [9].

Taking into consideration both the increased levels of HS in the context of chronic respiratory diseases and their potential involvement in the pathogenesis, the disruption of the interaction between HS and cytokines/chemokines may impact the inflammatory response. Specific GAG mimetics have been used to target some of these interactions in in vitro models [10]. In this context, we recently tested and characterized several synthesized HS competitors, in particular chemically modified derivatives of heparin with attenuated anticoagulant activity. These HS competitors not only bind to cytokines/chemokines [10], as natural endogenous HS does, but also inhibit the activity of neutrophil elastase (NE), a protease involved in the progression of lung fibrosis and in the sustainment of the inflammatory response in chronic respiratory diseases.

To date, the relevance of HS during P. aeruginosa infections, that characterize many chronic respiratory diseases, has not yet been addressed. Here, we utilized mouse models of lung infection to (i) investigate whether chronic $P$. aeruginosa lung infection may impact HS composition, and (ii) explore the potential anti-inflammatory activity of synthesized HS competitors in vivo. We report that: (i) chronic P. aeruginosa lung infection increased the levels of specific HS disaccharide building blocks; (ii) two HS competitors, in particular an $\mathrm{N}$-acetyl heparin and a glycol-split heparin, named respectively $\mathrm{C} 23$ and $\mathrm{C} 3{ }_{\mathrm{gs} 20}$, reduced the inflammatory response during acute and chronic $P$. aeruginosa lung infections, and decreased also the bacterial burden in a model of long-term chronic airways colonization.

\section{Results}

\subsection{Evaluation of Specific HS Disaccharides and Their Levels in a Murine Model of Chronic P. aeruginosa Airways Infection}

Taking into consideration the increased levels of GAGs in the lungs of mice chronically infected with $P$. aeruginosa for 28 days [11], we evaluated GAG species in this mouse model of chronic airway infection. C57Bl/6NcrlBR mice were inoculated with P. aeruginosa AA43 isolate embedded in agar-beads and with sterile agar beads (Ctrl group). After 28 days murine lungs were homogenized, centrifuged and supernatants were separated from pellets to distinguish released GAGs from those 
present as structural components of the extracellular matrix, respectively. Only lungs from mice that were still infected at 28 days post-challenge were analysed for their GAG content by selective enzymatic digestion [12,13]. High performance liquid chromatography-mass spectrometry (HPLC-MS) profiles of digestion products showed the presence of oligosaccharides from heparin/HS (Figure 1a and Supplementary Figure S1b), but not from other GAGs such as CS or DS. The amount of CS/DS was probably under the limit of detection. Digestion with heparinases lyases produced mainly disaccharides and traces of tetrasaccharides and hexasaccharides. It is known that the presence of the 3-O-sulfated glucosamine renders the glycosidic bond between $\mathrm{N}$-acetylated, 6-O-sulfated glucosamine and the unsulfated glucuronic acid impervious to the action of heparinases [14]. Indeed, we detected tetrasaccharides probably bearing the trisulfated glucosamine residue like $\Delta 4,4,0$, but also other tetrasaccharides, i.e., $\Delta 4,3,0$ and $\Delta 4,2,1$, probably due to a limited efficiency of the enzymatic digestion, despite the excess of enzymes. Thus, we considered the disaccharidic composition, that represents more than the $90 \%$ of the digestion products in both infected and uninfected mice. The overall composition of digestion products indicated the presence of HS-like structure rather than heparin, due to the scarce presence of the trisulfated disaccharide $(\Delta 2,3,0)$ and the high presence of monosulfated or monoacetylated disaccharides $(\Delta 2,1,0$ and $\Delta 2,1,1)$. Indeed, comparing the integrals of HPLC peaks of disaccharides to the sum of the relative integrals (Figure 1b), an increase in digestion products in infected mice when compared to control uninfected mice was observed, with the prevalence of the monosulfated and disulfated disaccharides over the other species detected. More in details, this difference was observed in pellets of lung homogenates (Supplementary Figure S1a), indicating that chronic $P$. aeruginosa lung infection increased the levels of structural HS. Differently, no significant differences were found in the supernatants of infected lungs compared to those of Ctrl uninfected lungs (Supplementary Figure S1a,b).

\subsection{Structure and Efficacy of Synthesized HS Competitors in the Mouse Model of Acute P. aeruginosa Airways Infection}

We designed and characterized specific heparin derivatives to generate compounds able to act as competitors of endogenous HS in the murine lung. In particular, these HS competitors have been prepared starting from unmodified pig mucosal heparin (PMH) (Table 1) by targeted chemical modification able to strongly diminish/abolish its anticoagulant activity while maintaining the ability to interact with other proteins [10]. The first set of HS competitors included glycol-split heparin $\mathrm{C}_{\mathrm{gs} 20}$ and $\mathrm{N}$-acetyl heparin C23, prepared as described previously [15]. In Figure 2, the major repeating disaccharide unit of heparin derivatives and the structure of the glycol-split uronic acid are shown.

Size is an important parameter that can influence the binding of HS competitors to proteins, especially the minimum length that is required to establish an interaction. For the second set of HS competitors to be tested, two structurally low molecular weight (LMW) analogues of $\mathrm{C}_{\mathrm{gs} 20}$ and C23 have been prepared by controlled reductive deamination, in order to improve the bio-availability of compounds and to verify the influence of dimensions on the activity of derivatives. In addition, the second set of synthesized HS competitors included compounds MMW C $3_{\mathrm{gs} 90}$ and MMW C $3_{\mathrm{gs} 45}$, that have been partially desulfated in order to increase the percentage of non-sulfated uronic acids reactive to the glycol-splitting modification to obtain a higher percentage of flexible joints along the chains. The MW of the first and second sets of compounds prepared (Table 1) ranged from 8 to $17.2 \mathrm{kDa}$, assuring an interaction with both IL-8 and human NE (12-14-mers for NE and 18-mer for IL-8) [16,17] which are known to be relevant to chronic inflammatory conditions. Notably, under controlled periodate oxidation conditions it is possible to limit the cleavage of glycosidic bonds without significant depolymerization of the HS competitors, as in the case of $\mathrm{C} 3_{\mathrm{gs} 20}$. Nevertheless, the combination of desulfation followed by glycol-splitting led to decrease in the MW of MMW C $3_{g s 45}$ and MMW C $3_{g s 90}$ proportionally to the increase of glycol-splitting, as expected. 


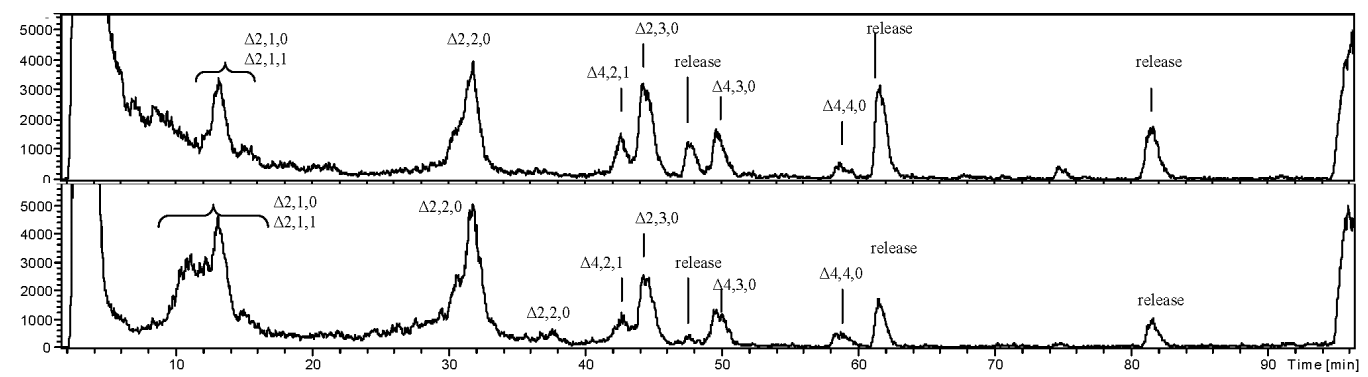

(a)

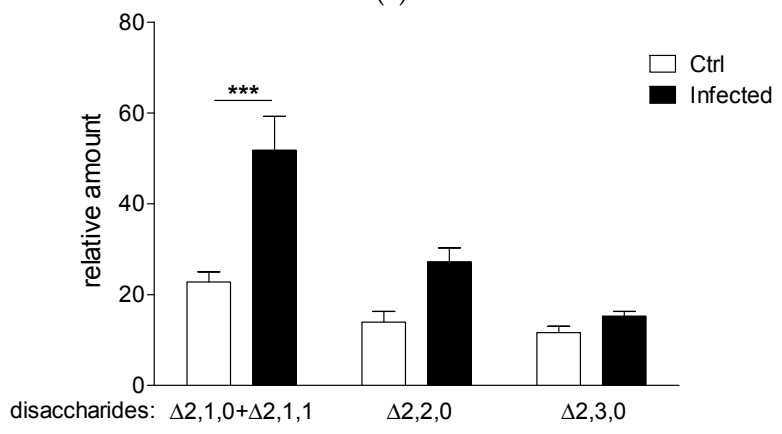

(b)

Figure 1. Disaccharide products of the digestion of heparin/HS from murine lungs after chronic $P$. aeruginosa infection. C57Bl/6NcrlBR mice were intratracheally injected with $1-2 \times 10^{6}$ colony forming units (CFUs) of P. aeruginosa isolate AA43 embedded in agar-beads (Infected) or with sterile agar-beads (Ctrl). After 28 days, lungs were perfused, recovered, homogenized and separated into pellets and supernatants. After removal of proteins, lipids and DNA, the presence of GAGs was verified by NMR. Samples were digested with a cocktail of heparin lyases to selectively degrade heparin/HS and recovered digestion products were desalted and finally analyzed by HPLC-MS. (a) Base Peak Chromatogram of digestion products from the pellet of one Ctrl uninfected (upper panel) and one infected (lower panel) lung homogenate from C57Bl/6NcrlBR mice. The unsaturated bond of the terminal uronic acid is indicated by $\Delta$, and the number of monomers, the number of sulfates and the number of acetyls are reported; (b) The graph shows the amount of each disaccharide species detected in the whole lung of an infected and an uninfected Ctrl mouse; $100 \%$ is considered the sum of peak areas of one whole lung from infected mouse lungs containing the highest amount of disaccharides. The data are pooled from at least two independent experiments $(n=6-15)$. Data are the mean \pm standard error of the mean (SEM) of at least three samples per type which have been processed independently. Statistical significance is indicated: ${ }^{* * *} p<0.001$.

Table 1. Structural characteristics of synthesized HS competitors originating from PMH (MW $20 \mathrm{kDa}$, $\%$ NAc 15).

\begin{tabular}{|c|c|c|c|}
\hline HS Competitors & MW (kDa) & $N$-acetyl (\%) & Glycol-Split (\%) \\
\hline $\mathrm{C} 23$ & 17.2 & 100 & 0 \\
\hline $\mathrm{C} 3_{\mathrm{gs} 20}$ & 16.5 & 14.6 & 20 \\
\hline LMW C23 & 8 & 91 & 0 \\
\hline LMW C3 $3_{\text {gs20 }}$ & 8 & 14.6 & 18 \\
\hline MMW C3 $3_{\mathrm{gs} 45}$ & 12.6 & 14.6 & 45 \\
\hline MMW C 3 gs 90 & 9.6 & 14.6 & 90 \\
\hline
\end{tabular}

The average molecular weight (MW), percentage of $N$-acetyl substitution in glucosamine residues and percentage of glycol-split (gs) uronate residues (cleavage by periodate oxidation of vicinal diols in unsubstituted D-GlcA and L-IdoA residues) is reported. Samples MMW C $3_{\mathrm{gs} 90}$ and $M M W ~ C 3_{g s 45}$ have been partially desulfated in order to increase the percentage of uronic acids reactive for the glycol-splitting modification. Samples LMW C23 and LMW $\mathrm{C}_{\mathrm{gs} 20}$ have been obtained by controlled reductive deamination of PMH. LMW, low MW; MMW, medium MW. 


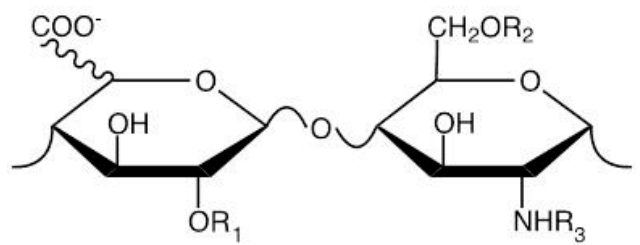

(a)

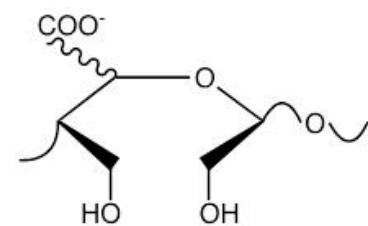

(b)

Figure 2. Structures and characteristics of synthesized HS competitors. The repeating disaccharide unit of compounds $\left(\mathrm{R}_{1}\right.$ and $\left.\mathrm{R}_{2}=\mathrm{H} / \mathrm{SO}_{3}{ }^{-}, \mathrm{R}_{3}=\mathrm{H} / \mathrm{SO}_{3}{ }^{-} / \mathrm{COCH}_{3}\right)$ is shown. The uronic acid is predominantly in the form L-iduronic acid (L-IdoA and L-IdoA-2-O-sulfate; $80 \%$ ) with D-glucuronic acid (D-GlcA; 20\%) making up the remainder. (a) Structure of the canonical disaccharide building block of heparin; (b) The glycol-split uronic acid residue present in compounds $\mathrm{C}_{\mathrm{gs} 20}, \mathrm{MMW} \mathrm{C} 3_{\mathrm{gs} 90}$ and MMW C3 $3_{\text {gs } 45}$.

Heparin derivatives have been shown to exert beneficial effects in inflammation [18]. We thus evaluated the impact of $\mathrm{C}_{\mathrm{gs} 20}$ and $\mathrm{C} 23$ on leukocyte recruitment in the murine BALF following acute $P$. aeruginosa lung infection. Mice were infected with the P. aeruginosa AA2 isolate [11,19], known to be highly virulent, and treated subcutaneously with these compounds $(30 \mathrm{mg} / \mathrm{kg})$. We found that neither $\mathrm{C} 23$ nor $\mathrm{C} 3_{\mathrm{gs} 20}$ affected the lung bacterial burden when compared to the vehicle (Figure $3 \mathrm{a}$ ). C23 significantly reduced the number of total leukocytes in comparison to the vehicle (Figure $3 b$ ) and in particular neutrophils (Figure 3c) in the BALF, although the neutrophil percentages were not significantly different between mice treated with the compound and those treated with the vehicle (C23 vs. vehicle $p=0.057$ ). Differently, C $3_{\mathrm{gs} 20}$ had only moderate inhibitory effects on leukocyte recruitment. C23 significantly reduced also IL-6, IL-12 (p40), granulocyte colony-stimulating factor (G-CSF) and monocyte chemoattractant protein-1 (MCP-1) when compared to the vehicle (Table 2). $\mathrm{C}_{\text {gs20 }}$ reduced inflammatory mediators but at lower extent and with a statistically significant difference only for IL-6 levels (Table 2). Differently, when the second set of HS competitors, including LMW $\mathrm{C} 3_{\mathrm{gs} 20}$, LMW C23, MMW C3 ${ }_{\mathrm{gs} 90}$ and MMW C3 ${ }_{\mathrm{gs} 45}$, were tested in this murine model, they did not affect either the bacterial burden or the recruitment of leukocytes, including neutrophils, in the BALF (Supplementary Figure S2).

Overall, these results indicate $\mathrm{C} 23$ and $\mathrm{C} 3_{\mathrm{gs} 20}$ as the most promising anti-inflammatory compounds in the mouse model of acute $P$. aeruginosa lung infection.

Table 2. Levels of cytokines and chemokines in murine lungs during acute P. aeruginosa lung infection $(6 \mathrm{~h})$ and subcutaneous treatment with $\mathrm{C}_{\mathrm{gs} 20}$ or $\mathrm{C} 23(30 \mathrm{mg} / \mathrm{kg})$.

\begin{tabular}{|c|c|c|c|c|c|}
\hline \multirow{2}{*}{ Cytokine/Chemokine } & \multicolumn{3}{|c|}{ Level (pg/500 $\mu$ g Lung) } & \multicolumn{2}{|c|}{$p$ Value } \\
\hline & Vehicle & $\mathrm{C} 3_{\mathrm{gs} 20}$ & $\mathrm{C} 23$ & $\mathrm{C} 3_{\text {gs20 }}$ vs. Vehicle & C23 vs. Vehicle \\
\hline IL-4 & $3.31 \pm 0.27$ & $3.54 \pm 0.19$ & $3.37 \pm 0.63$ & ns & ns \\
\hline IL-6 & $232.9 \pm 8.53$ & $176.9 \pm 15.95$ & $159.7 \pm 7.14$ & ** & $* * *$ \\
\hline IL-12p40 & $10.97 \pm 0.79$ & $9.21 \pm 0.76$ & $7.86 \pm 0.68$ & ns & * \\
\hline IL-12p70 & $83.98 \pm 3.46$ & $93.98 \pm 9.67$ & $87.04 \pm 6.45$ & ns & ns \\
\hline IL-13 & $124.68 \pm 8.49$ & $140.26 \pm 6.32$ & $114.37 \pm 5.33$ & ns & ns \\
\hline IL-17A & $6.77 \pm 0.78$ & $6.85 \pm 0.21$ & $6.66 \pm 0.99$ & ns & ns \\
\hline Eotaxin & $353.62 \pm 22.52$ & $450.79 \pm 33.85$ & $341.3 \pm 71.56$ & ns & ns \\
\hline G-CSF & $542 \pm 10.56$ & $465.8 \pm 37.58$ & $426.9 \pm 36.53$ & ns & * \\
\hline IFN- $\gamma$ & $538.19 \pm 15.12$ & $525.13 \pm 72.72$ & $462.34 \pm 54.04$ & ns & $\mathrm{ns}$ \\
\hline MCP-1 & $1327 \pm 89.7$ & $1239 \pm 111.1$ & $864.2 \pm 118.6$ & ns & * \\
\hline MIP-1 $\beta$ & $1302.61 \pm 124.2$ & $1308.63 \pm 142.3$ & $1003.01 \pm 191.9$ & ns & ns \\
\hline RANTES & $195.83 \pm 19.19$ & $247.57 \pm 39.04$ & $248.55 \pm 46.88$ & ns & ns \\
\hline
\end{tabular}

Data are expressed as mean \pm SEM. Statistical significance is indicated: ${ }^{*} p<0.05,{ }^{* *} p<0.01,{ }^{* * *} p<0.001$. ns: not significant. MIP-1 $\beta$, macrophage inflammatory protein-1 $\beta$; RANTES, regulated on activation normal T expressed and secreted. 


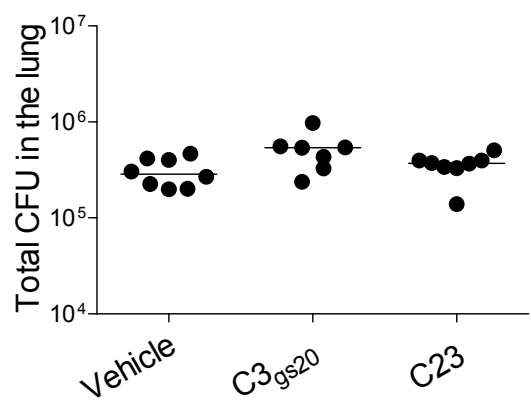

(a)

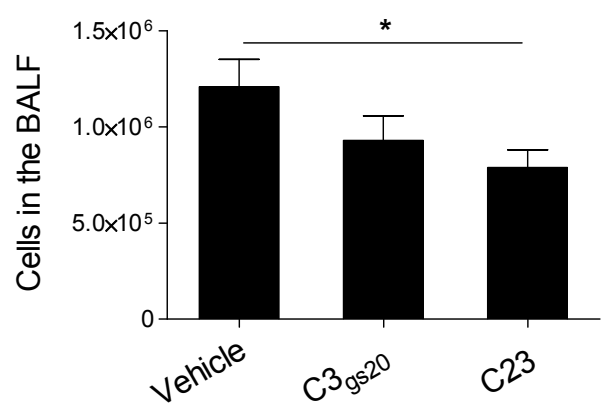

(b)

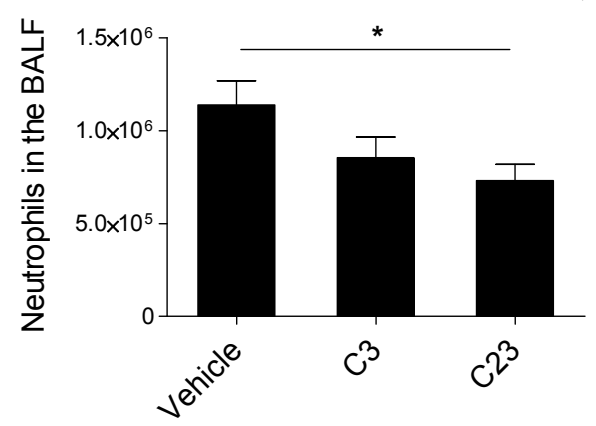

(c)

Figure 3. Modulation of the host response by synthesized HS competitors in a mouse model of acute $P$. aeruginosa lung infection. C57Bl/6NcrlBR mice were intratracheally injected with $5 \times 10^{6}$ CFUs of the highly virulent $P$. aeruginosa isolate AA2. Mice were subcutaneously treated with HS competitors $(30 \mathrm{mg} / \mathrm{kg}$ ) or their vehicle two hours before and two hours after the challenge and sacrificed $6 \mathrm{~h}$ post-infection. BALF and lung were recovered. (a) Total CFUs in the lungs were evaluated; (b) Total cell and (c) neutrophil recruitment was analyzed in BALF. The data are pooled from at least two independent experiments $(n=7-8)$. CFUs in individual mice are represented as dots and horizontal lines represent median values. Cells are represented as mean \pm SEM. Statistical significance is indicated: * $p<0.05$.

\subsection{Efficacy of Synthesized HS Competitors in Mouse Models of Chronic P. aeruginosa Airways Infection}

Next, we tested the ability of HS competitors to reduce inflammation during the development and the course of chronic $P$. aeruginosa lung infection. First, we evaluated the effect of $\mathrm{C} 3_{\mathrm{gs} 20}$ and $\mathrm{C} 23$ in an agar-beads mouse model of chronic lung infection running for 14 days. C57Bl/6NcrlBR mice were chronically infected with P. aeruginosa AA43 isolate, known to persist in the lung with an incidence of colonization around 30-40\% [11], and treated subcutaneously with $\mathrm{C} 3_{\mathrm{gs} 20}$ and $\mathrm{C} 23$ starting from the day of infection. We found that the incidence of chronic lung colonization was reduced in mice infected with $\mathrm{C}_{\mathrm{gs} 20}$ when compared to those treated with the vehicle $\left(13 \%\right.$ for $\mathrm{C}_{\mathrm{gs} 20}$ and $33 \%$ for C23 vs. 33\% for vehicle; Figure $4 a$ ), although this difference did not reach statistical significance. We also observed a trend to a decrease in lung CFUs in mice treated with $\mathrm{C}_{\mathrm{gs} 20}$ in comparison to vehicle (Figure $4 \mathrm{~b}$ ). In addition, C23 significantly reduced the recruitment of total leukocytes, including neutrophils, in comparison to vehicle (Figure $4 \mathrm{c}, \mathrm{d}$ ). A similar trend was observed also for $\mathrm{C}_{\mathrm{gs} 20}$. 

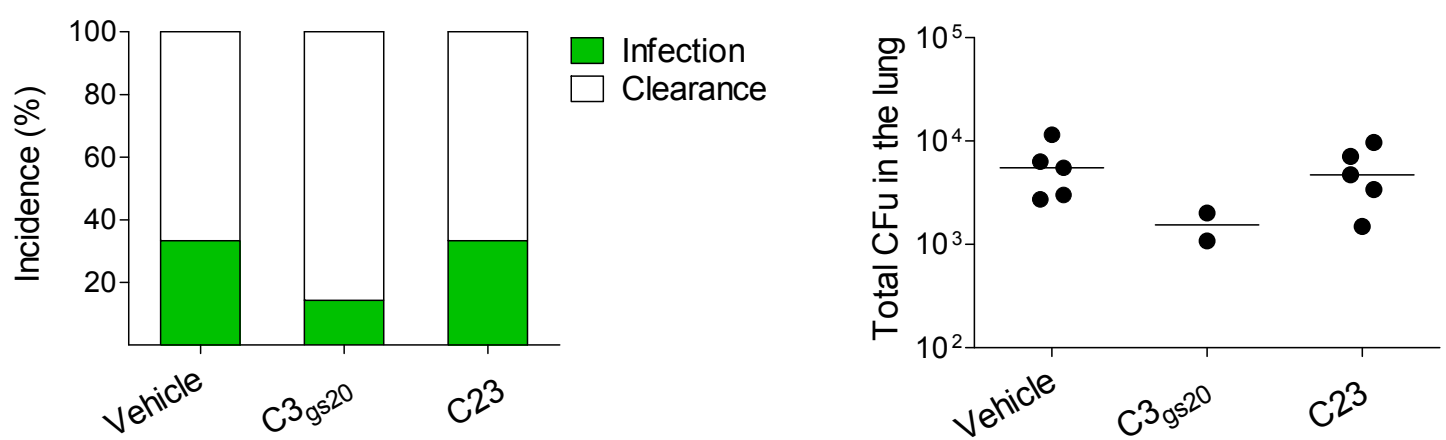

(a)

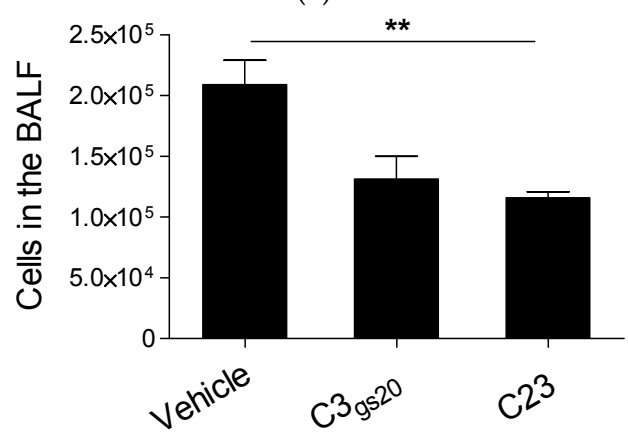

(c)

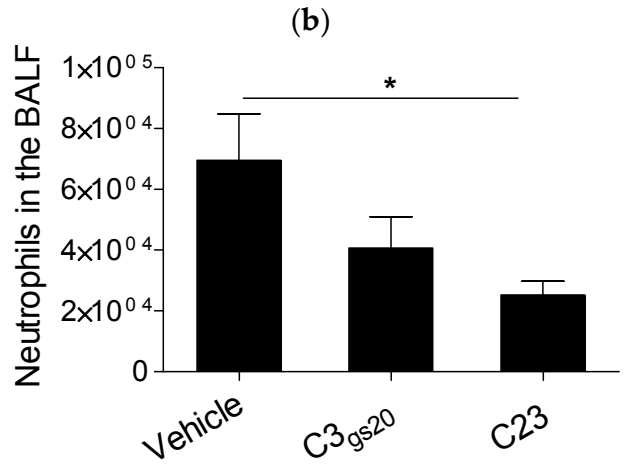

(d)

Figure 4. Modulation of the host response by synthesized HS competitors in a mouse model of chronic P. aeruginosa lung infection (14 days). C57Bl/6NcrlBR mice were intratracheally injected with 1-2 $\times 10^{6}$ CFUs of the $P$. aeruginosa isolate AA43 embedded in agar-beads. Mice were treated subcutaneously with HS competitors $(30 \mathrm{mg} / \mathrm{kg}$ ) or vehicle every day starting from the day of infection for 14 days. At the sacrifice, BALF and lung were recovered. (a) Bacterial clearance (white) and incidence of colonization (green) were determined; (b) CFUs were evaluated in total lung of mice still infected at the sacrifice. Total cell (c) and neutrophil (d) recruitment was analyzed in BALF. The data are pooled from two independent experiments $(n=14-15)$. CFUs in individual mice are represented as dots and horizontal lines represent median values. Cells are represented as mean \pm SEM. Statistical significance is indicated: ${ }^{*} p<0.05,{ }^{* *} p<0.01$.

We then investigated whether $\mathrm{C} 3_{\mathrm{gs} 20}$ and C23 also impacted an established chronic P. aeruginosa lung infection. Thus, we extended the P. aeruginosa chronic infection for 28 days and started the treatment with HS competitors and vehicle after ten days from the infection, once chronic infection is well-established [20]. We previously showed that this mouse model of $P$. aeruginosa persistence is highly stable in terms of incidence of colonization and bacterial burden up to three months, and reproduces detectable chronic inflammation and tissue damage for long-term [11,20]. By using this schedule of treatment, the incidence of chronic $P$. aeruginosa lung colonization was not affected by HS competitors and remained stable (percentages of mice still colonized after 28 days: vehicle, $30.4 \%$; $\mathrm{C} 3$ gs20, 30\%; C23, 30.8\%). However, $\mathrm{C} 3$ gs20 and C23 significantly increased murine body weights when compared with the vehicle, indicating that they promoted a better health status (Figure 5a). In addition, $\mathrm{C}_{\mathrm{gs} 20}$ and $\mathrm{C} 23$ significantly decreased the bacterial burden in the lung in comparison to the vehicle (Figure $5 \mathrm{~b}$ ). C $3_{\text {gs20 }}$ significantly decreased the infiltration of leukocytes, including neutrophils, in the BALF (Figure 5c,d), and the levels of inflammatory mediators, such as IL-1 $\beta$, IL-12p70, IL-17A, G-CSF and KC in comparison to the vehicle (Table 3). C23 showed a similar trend, although only the differences of leukocyte infiltration and IL-17A level reached a statistical significance (Figure 5c and Table 3). Other markers were not affected by these compounds as shown in Table 3. 


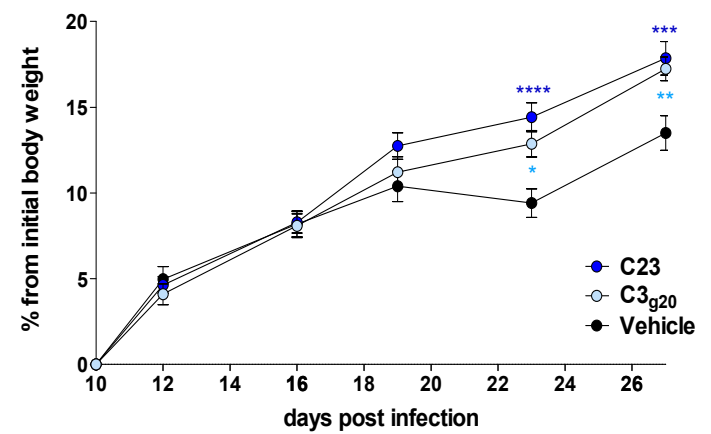

(a)

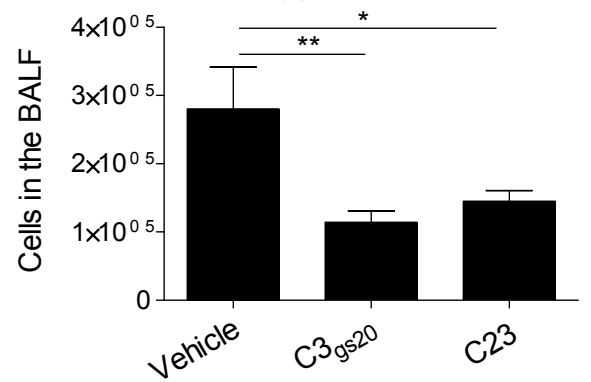

(c)

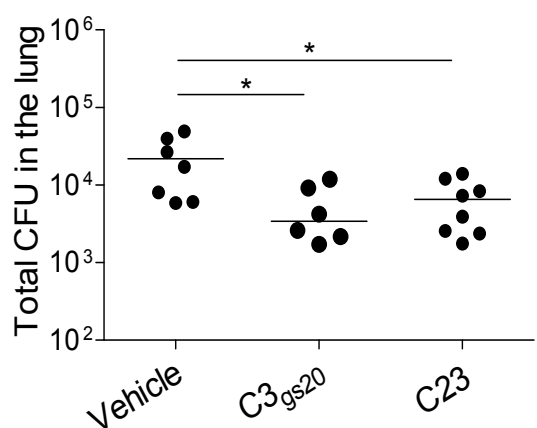

(b)

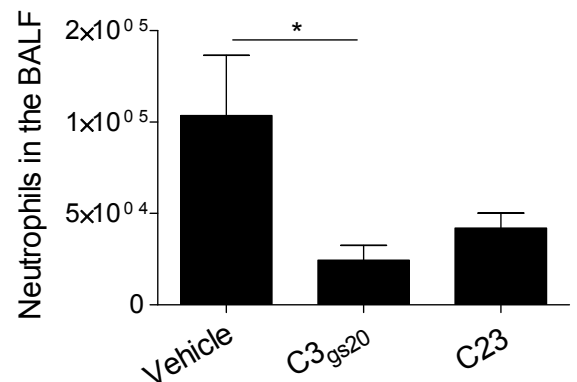

(d)

Figure 5. Modulation of the host response by synthesized HS competitors in a mouse model of long-term chronic $P$. aeruginosa lung infection (28 days). C57Bl/6NcrlBR mice were intratracheally injected with 1-2 $\times 10^{6}$ CFUs of the P. aeruginosa isolate AA43 embedded in agar-beads. Mice were treated subcutaneously with HS competitors $(30 \mathrm{mg} / \mathrm{kg}$ ) or vehicle every day starting from ten days post-infection. At the sacrifice, BALF and lung were recovered. (a) Changes from initial body weight were calculated for each group of mice at regular intervals. (b) Total CFUs in the lungs were evaluated. (c) Total cell and (d) neutrophil recruitment was analyzed in BALF. The data are pooled from at least two independent experiments $(n=20-26)$. CFUs in individual mice are represented as dots and horizontal lines represent median values. The other parameters are represented as mean \pm SEM. Statistical significance is indicated: ${ }^{*} p<0.05,{ }^{* *} p<0.01,{ }^{* * *} p<0.001,{ }^{* * * *} p<0.0001$.

Table 3. Levels of cytokines and chemokines in murine lungs during chronic $P$. aeruginosa lung infection (28 days) and subcutaneous treatment with $\mathrm{C} 3_{\mathrm{gs} 20}$ or $\mathrm{C} 23(30 \mathrm{mg} / \mathrm{kg}$ ).

\begin{tabular}{|c|c|c|c|c|c|}
\hline \multirow{2}{*}{ Cytokine/Chemokine } & \multicolumn{3}{|c|}{ Level (pg/500 $\mu$ g Lung) } & \multicolumn{2}{|c|}{$p$ Value } \\
\hline & Vehicle & $\mathrm{C} 33_{\mathrm{gs} 20}$ & $\mathrm{C} 23$ & $\mathrm{C} 3_{\text {gs20 }}$ vs. Vehicle & C23 vs. Vehicle \\
\hline IL-1 $\alpha$ & $26 \pm 3.14$ & $6.91 \pm 0.47$ & $7.75 \pm 0.75$ & $\mathrm{~ns}$ & $\mathrm{~ns}$ \\
\hline IL-1 $\beta$ & $24.04 \pm 4.92$ & $10.42 \pm 2.11$ & $15.93 \pm 2.63$ & * & ns \\
\hline IL-2 & $4.49 \pm 1.10$ & nd & nd & $\mathrm{n} / \mathrm{a}$ & $\mathrm{n} / \mathrm{a}$ \\
\hline IL-5 & $2.96 \pm 0.37$ & $2.85 \pm 1.03$ & $3.52 \pm 0.60$ & ns & ns \\
\hline IL-9 & $99.56 \pm 12.57$ & $132.10 \pm 24.21$ & $116.00 \pm 19.28$ & ns & ns \\
\hline IL-10 & $3.89 \pm 0.25$ & $3.10 \pm 0.84$ & $3.19 \pm 0.47$ & ns & ns \\
\hline IL-12p40 & $11.27 \pm 1.07$ & $10.15 \pm 1.13$ & $10.20 \pm 0.49$ & ns & ns \\
\hline IL-12p70 & $8.93 \pm 1.17$ & $4.62 \pm 1.19$ & $5.74 \pm 0.90$ & $*$ & ns \\
\hline IL-13 & $98.20 \pm 14.41$ & $76.03 \pm 14.45$ & $98.11 \pm 14.37$ & ns & ns \\
\hline IL-17A & $7.94 \pm 1.27$ & $3.29 \pm 0.66$ & $4.41 \pm 0.90$ & $* *$ & $*$ \\
\hline Eotaxin & $264.20 \pm 30.39$ & $135.20 \pm 49.53$ & $237.40 \pm 34.22$ & ns & $\mathrm{ns}$ \\
\hline G-CSF & $4.62 \pm 0.95$ & $2.57 \pm 0.54$ & $3.89 \pm 0.21$ & $*$ & ns \\
\hline GM-CSF & $29.95 \pm 2.66$ & nd & $28.82 \pm 10.48$ & $\mathrm{n} / \mathrm{a}$ & ns \\
\hline IFN- $\gamma$ & $5.22 \pm 0.71$ & $3.90 \pm 1.03$ & $6.13 \pm 0.79$ & ns & ns \\
\hline $\mathrm{KC}$ & $13.92 \pm 2.64$ & $7.91 \pm 0.69$ & $11.71 \pm 1.47$ & * & ns \\
\hline MCP-1 & $84.93 \pm 9.12$ & $70.74 \pm 12.04$ & $67.41 \pm 7.78$ & $\mathrm{~ns}$ & ns \\
\hline MIP-1 $\beta$ & $16.94 \pm 1.99$ & $15.80 \pm 2.38$ & $16.04 \pm 2.05$ & ns & ns \\
\hline RANTES & $6.95 \pm 0.59$ & $6.86 \pm 1.04$ & $8.47 \pm 1.07$ & ns & ns \\
\hline TNF- $\alpha$ & $6.59 \pm 0.33$ & $4.44 \pm 0.63$ & $7.55 \pm 0.81$ & ns & ns \\
\hline
\end{tabular}

Data are expressed as mean \pm SEM. Statistical significance is indicated: ${ }^{*} p<0.05,{ }^{* *} p<0.01$. ns: not significant; nd: not detectable; n/a: not applicable. GM-CSF, granulocyte-macrophage colony-stimulating factor; $\mathrm{KC}$, keratinocyte chemoattractant, TNF- $\alpha$, tumor necrosis factor alpha. 
When we tested the impact of other HS competitors on the host response in this mouse model of chronic lung infection, we found that neither MMW C $3_{\mathrm{gs} 90}$ nor $\mathrm{MMW} \mathrm{C}_{\mathrm{gs} 45}$ affected either bacterial burden or leukocytes recruitment (Supplementary Figure S3).

Overall these results indicated that $\mathrm{C}_{\mathrm{gs} 20}$ and $\mathrm{C} 23$ have a dual effect: on inflammation, containing leukocyte recruitment in the site of infection, and on infection, reducing the bacterial load.

Taking into consideration the effect of $\mathrm{C}_{\mathrm{gs}_{\mathrm{g}} 20}$ and $\mathrm{C} 23$ on P. aeruginosa bacterial burden in the mouse model of chronic P. aeruginosa infection, we asked whether $\mathrm{C}_{\mathrm{gs} 20}$ and $\mathrm{C} 23$ could have any anti-bacterial activity. We did not find any change in minimum inhibitory concentrations after challenge with up to $512 \mu \mathrm{g} / \mathrm{mL}$. When we investigated the effect on biofilm formation, both $\mathrm{C} 3_{\mathrm{gs} 20}$ and C23 induced a statistically significant reduction of AA43 sessile fraction in a dose-dependent fashion (Figure 6). These data suggest an inhibitory effect exerted by $\mathrm{C} 3_{\mathrm{gs} 20}$ and $\mathrm{C} 23$ on P. aeruginosa biofilm formation.

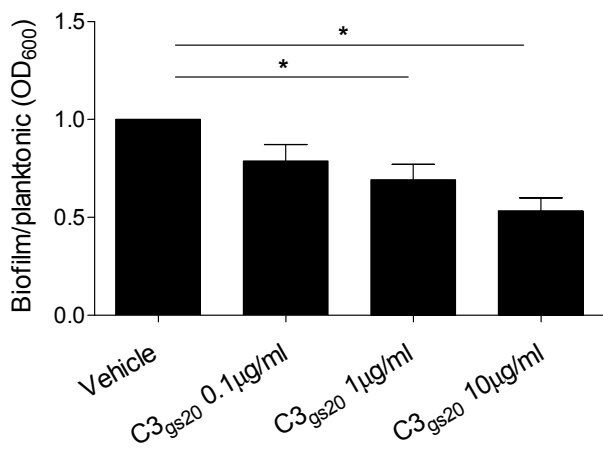

(a)

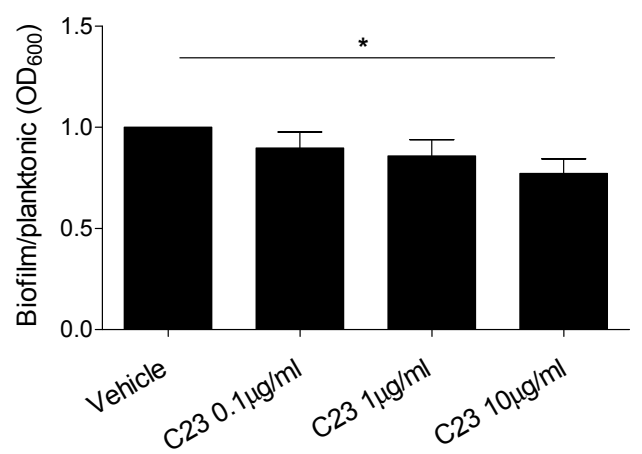

(b)

Figure 6. Effect of synthesized HS competitors on P. aeruginosa biofilm formation. P. aeruginosa strain AA43 was grown for $24 \mathrm{~h}$ at $37^{\circ} \mathrm{C}$ either in the absence or presence of different concentrations of $\mathrm{C}_{\text {gs20 }}(\mathbf{a})$ and $\mathrm{C} 23(\mathbf{b})$. Biofilm biomass was quantified by staining with crystal violet and absorbance measurements at $\mathrm{OD}_{600}$. Absorbance of planktonic bacteria in the culture medium was measured at $\mathrm{OD}_{600}$. Results are expressed as the ratio between biofilm absorbance and planktonic bacteria absorbance normalized on the value obtained for AA43 treated with isotonic saline (vehicle). The data derive from three independent experiments in triplicate. Values represent the mean \pm SEM. Statistical significance is indicated: ${ }^{*} p<0.05$.

\section{Discussion}

Increased levels of GAGs including HS, the most abundant in the lung parenchyma, are common to several chronic respiratory diseases, including CF, COPD and IPF $[1,2,5]$. Whether P. aeruginosa infections may contribute to the increase of HS is still an open question. Clinical data are difficult to interpret due to the large number of confounding variables. Here, using mouse models of lung infection, we demonstrated that long-term chronic P. aeruginosa lung infection induces structural changes in HS as shown by increased amounts of specific HS disaccharide building blocks. In addition, our results indicate that two synthesized HS competitors, in particular $\mathrm{N}$-acetyl heparin and glycol-split heparin, named respectively $\mathrm{C} 23$ and $\mathrm{C} 3_{\mathrm{gs} 20}$, competing with endogenous HS, dampen the inflammatory response induced by $P$. aeruginosa and reduce the bacterial burden.

To our knowledge, despite several reports indicating increased levels of highly sulfated HS in the airways of patients affected by chronic respiratory diseases, there are no studies analyzing specifically the impact of bacterial infections on HS levels and composition in the lung. We previously demonstrated that $P$. aeruginosa persistence was associated with a progressive increase of sulfated GAGs in murine lungs [11]. Here, we focused on HS composition and found that long-term chronic P. aeruginosa lung colonization led to an increase of specific HS disaccharides, in particular mono- and di-sulfated ones, in the pellet of murine lungs. This finding suggests that $P$. aeruginosa infection increases mainly structural HS, rather than contributing to released HS. In this regard, HS 
has been detected also in the BALF in COPD patients [8] and in the sputum sol of patients with bronchiectasis [21] indicating HS degradation. However, no reports indicate a correlation between HS levels in airway secretions and bacterial infection. Future clinical studies should determine a potential correlation between bacterial infections/colonization, including by P. aeruginosa, and the levels and sulfation of HS in the lungs of patients with chronic respiratory diseases. In addition, we analyzed the $\mathrm{HS}$ composition in the lung of $\mathrm{C} 57 \mathrm{Bl} / 6 \mathrm{NcrlBR}$ mice. Since the murine genetic background determines infection outcomes [22-24], it would be interesting to clarify whether it can also affect the composition of the extracellular matrix by using different inbred and outbred murine lines.

Besides maintaining lung tissue structure, HS may modulate the behavior of cells by binding growth factors and by interacting with cell surface receptors [4,25]. In addition, it can interact with proteases and cytokines/chemokines impacting on immunopathology. Taking into consideration these evidences and our findings on the increase of HS during chronic P. aeruginosa lung infection, we explored a HS inhibitory strategy in mouse models of infection. We chose to chemically modify heparin to synthesize competitors of the endogenous HS, thanks to its structural similarity to HS and its commercial availability; moreover, it is commonly used in hospitals as an anticoagulant drug and considered to be safe. Recently, these synthesized HS competitors with low or absent anticoagulant activity have been shown to bind to IL- 8 and TNF- $\alpha$ and to inhibit the activity of NE in vitro [10], suggesting that these compounds could preserve the connective tissues and limit inflammation in vivo. When tested in murine models, $\mathrm{C} 23$ and $\mathrm{C} 3_{\mathrm{gs} 20}$ reduced neutrophilic recruitment and cytokines/chemokines production both in acute and chronic P. aeruginosa lung infection. These results support the finding that HS binding to chemokines may contribute to leukocyte recruitment in the site of infection/injury by generating the chemotactic gradient as well as increasing pro-inflammatory activities of chemokines by protecting them from proteolytic degradation [5-7]. It can be hypothesized that synthesized HS competitors may reduce levels of endogenous HS, thus reducing the chemotactic gradient. In this regard, a HS reduction secondary to decreased inflammation and infection may be plausible after long-term chronic lung infection. However, it would be unlikely that these compounds can directly reduce HS, taking into account their effects after short-term acute P. aeruginosa infection. Differently, we speculate that synthesized HS competitors could have competed with endogenous HS for the binding to cytokines/chemokines, thus leading to their degradation/elimination. Further studies to elucidate these mechanisms are necessary, in particular to evaluate the amount of chemokines still bound to endogenous HS during treatment with synthesized HS competitors in vivo. Anyhow, the reduction of neutrophilic recruitment could lead to a decreased immunopathology by itself, since it implies lower levels of neutrophil proteases, including NE. In addition, taking into consideration that HS competitors inhibit NE activity [10], reduced tissue remodeling and fibrosis could be expected. In fact, NE, a protease described as abundant in the airways of patients affected by chronic respiratory diseases [26], degrades several components of the extracellular matrix, including elastin [27], thus contributing to the tissue remodeling and fibrosis [4], and ultimately aggravating the immunopathology. In this context, several attempts to inhibit NE have been carried out, also in clinical studies on patients with respiratory diseases, although with contrasting results [26].

One of the off-target effects of anti-inflammatory treatments is the impairment of the host defense that can lead to the exacerbation of the infection [20,28-30]. However, we did not observe an increase in $P$. aeruginosa burden in the model of acute lung infection. Next, we set-up two schedules of treatment in the mouse model of chronic lung infection. In the 14-day-lasting model of chronic lung colonization, mice had been treated starting from the day of infection. In such a model, synthesized HS competitors could interfere in particular with the early immune response, thus impacting the development and the progression of chronic lung infection. Differently, in the 28-day-lasting model of chronic lung colonization, mice were treated starting from ten days post-infection to evaluate effects of HS competitors on well-established chronic lung infection. In both schedules, we adopted the P. aeruginosa AA43 isolate, which can establish chronic infection in C57Bl/6NcrlBR mice with 
an incidence of colonization around $30-40 \%$ [11] starting from seven days post-infection. This choice is fundamental when the aim is determining the impact of anti-inflammatory treatment on the host defense, since an increase in the number of mice still colonized after long-term or in P. aeruginosa load could be observed. For instance, using this isolate we recently demonstrated that the IL-17A pathway impairment increased both the incidence of colonization and bacterial burden [20]. Unexpectedly, $\mathrm{C}_{\mathrm{gs} 20}$ and C23 impacted P. aeruginosa infection and, in particular, they reduced the bacterial burden in murine lungs after long-term chronic lung infection.

When administered in different schedules of P. aeruginosa lung infection and treatment, $\mathrm{C} 3_{\mathrm{gs} 20}$ and C23 showed slight differences: C23 was more potent in inhibiting the inflammatory response in the model of acute lung infection, while $\mathrm{C} 3_{\mathrm{gs} 20}$ was more effective in the model of long-term chronic infection, where it decreased the bacterial burden, and it was more potent in hampering in vitro P. aeruginosa biofilm formation. We may speculate that these different activities may be addressed to the structures of synthesized HS competitors. Indeed, C23 is a $\mathrm{N}$-acetyl heparin, with charge density and distribution similar to that of HS. Therefore, it is potentially able to mimic HS in its interactions and to compete by sequestering cytokines/chemokines from endogenous HS, thus rendering them more susceptible to degradation. Differently from $\mathrm{C} 23, \mathrm{C} 3_{\mathrm{gs} 20}$ maintains the negative charge density of PMH and displays chain flexibility thanks to the glycol-split modification. In this context, its more potent anti-biofilm activity could be due to several interactions: (i) because of its negative charges, it could bind $\mathrm{Ca}^{++}$, known to form a bridge between polyanionic alginate molecules that stabilizes biofilms [31]; (ii) it could interact with biofilm polysaccharides, impeding their binding; (iii) it could counteract the binding between single P. aeruginosa cells. However, there could be other explanations to the decrease of $P$. aeruginosa burden after long-term chronic lung colonization following treatment with $\mathrm{C} 23$, and in particular $\mathrm{C}_{\mathrm{gs} 20}$. In fact, $\mathrm{HS}$ has been found to be a cell receptor for P. aeruginosa and a binding site for bacterial flagella, and this could suggest another role during infection [32,33]. Further studies based on additional structural modifications of these compounds could provide new insights into their biological activities during host-pathogen interplay. Moreover, the reduction of the bacterial burden by HS competitors during $P$. aeruginosa pneumonia suggests that the potential synergy between these compounds and antibiotics currently used in clinics should be investigated.

\section{Materials and Methods}

\subsection{Ethics Statement}

Animal studies strictly followed the Italian Ministry of Health guidelines for the use and care of experimental animals. This study was performed following protocols approved by the Institutional Animal Care and Use Committee (IACUC, protocols \#502 of 14 July 2011 and \#812 of 28 July 2016) of the San Raffaele Scientific Institute (Milan, Italy). Research with P. aeruginosa clinical strains has been approved by the responsible physician at the CF Center at Hannover Medical School, Germany. Additional information is available in the Supplementary Materials.

\subsection{Bacterial Strains}

Sequential P. aeruginosa isolates (AA2 and AA43) were recovered from CF patients and previously characterized for genotypic and phenotypic traits, and virulence [19,34,35]. AA2, expressing several virulence factors, including swimming motility, twitching motility and protease secretion, was isolated at the onset of chronic infection. Differently, AA43, a variant with adaptive phenotypes, including mucoidy, absence of swimming motility, low twitching motility and production of protease, was collected after seven years of chronic colonization. AA2 has previously been shown to induce high in vitro and in vivo acute virulence, while AA43 has been shown to be attenuated, but capable of developing chronic lung infection $[11,19,36]$. 


\subsection{Mouse Strain}

C57Bl/6NcrlBR (Charles River, Calco, Lecco, Italy), 8 to 10 weeks old, were maintained in specific pathogen-free conditions at the San Raffaele Scientific Institute (Milan, Italy).

\subsection{HS Competitors Synthesis and Characterization}

Compounds are HS competitors obtained by chemical modification of $\mathrm{PMH}$ in order to reduce the anticoagulant activity whilst maintaining the anti-inflammatory potential. In particular, the $\mathrm{N}$-acetyl heparin C23 and glycol-split heparin derivatives $\mathrm{C}_{\mathrm{gs} 20}, \mathrm{MMW} \mathrm{C} 3_{\mathrm{gs} 90}$ and MMW C3 $3_{\mathrm{gs} 45}$, were generated as previously described $[15,37]$ and characterized by ${ }^{13}$ C-NMR [10] (Supplementary Figure S4a). Additional information is available in the Supplementary Materials. In addition, two LMW variants of $\mathrm{C} 23$ and $\mathrm{C}_{\mathrm{gs} 20}$ were produced by depolymerization of $\mathrm{PMH}$ through reductive deamination with nitrous acid using a $\mathrm{NaNO}_{2}$ /heparin ratio of 1:7, as explained in detail in the Supplementary Materials, followed by the same modifications introduced on full-length derivatives. These LMW were characterized by HSQC-NMR (Supplementary Figure S4b). The average MWs were determined at a concentration of $5 \mathrm{mg} / \mathrm{mL}$ employing Viscotek HP-SEC-TDA as previously described [38].

\subsection{Mouse Models of Acute and Chronic P. aeruginosa Infection}

In the acute infection model, mice were injected intratracheally with $5 \times 10^{6}$ CFUs of planktonic P. aeruginosa AA2 isolate, following established procedures $[11,19,39]$. Mice were treated subcutaneously with $30 \mathrm{mg} / \mathrm{kg}$ of synthesized HS competitors [40-42] or with vehicle (isotonic saline) two hours before and two hours after infection, and sacrificed six hours post-infection.

In the chronic infection model, mice were injected intratracheally with $1-2 \times 10^{6}$ CFUs of P. aeruginosa AA43 isolate, embedded in agar beads, following established procedures [11,30,39]. The bacterial load was previously set-up as the minimum inoculum to establish chronic infection [43]. Another group of mice (Ctrl) was intratracheally injected with sterile beads. For the analysis of HS/heparin levels, one batch of infected mice and the Ctrl group were sacrificed after 28 days from the infection, lungs were perfused with isotonic saline to avoid the contamination by circulating HS/heparin, recovered, homogenized and centrifuged. Pellets and supernatants were separated and lyophilized. For the analysis of HS competitor efficacy, one batch of infected mice was treated once a day as described above starting from the day of infection and sacrificed 14 days post-infection. Another batch of mice was treated once a day as described above starting from ten days post-infection and sacrificed 28 days post-infection.

BALF and lung were recovered and processed, and total/differential cell count and bacterial burden evaluated, as previously described [39]. Further information on the procedures are present in the Supplementary Materials.

\subsection{HS/heparin Analysis in Murine Lungs}

Samples were defatted by washing with chloroform/methanol, then with ethyl ether and freeze-dried, recovered in dPBS with $2 \mathrm{mM} \mathrm{CaCl}_{2}$ and subjected first to proteolytic cleavage with Proteinase $\mathrm{K}$ at $55{ }^{\circ} \mathrm{C}$ for $48 \mathrm{~h}$, then to DNase I digestion at $37^{\circ} \mathrm{C}$ for $48 \mathrm{~h}$. After boiling for $10 \mathrm{~min}$ to stop the reaction, samples were filtered on $0.2 \mu \mathrm{m}$ filters, then purified by $3 \mathrm{kDa}$ ultrafiltration to remove digestion fragments. Purified samples were analyzed by ${ }^{1} \mathrm{H}-\mathrm{NMR}$ and eventually subjected to a second protease digestion. Digestion of CS by Chondroitinase ABC was carried out in a $50 \mathrm{mM}$ sodium acetate/phosphate buffer $(1: 1 \mathrm{v} / \mathrm{v}), \mathrm{pH} 8$ at $37^{\circ} \mathrm{C}$ for $48 \mathrm{~h}$. After inactivation by boiling for $10 \mathrm{~min}$ samples were filtered onto $0.45 \mu \mathrm{m}$ cut-off filters.

Digestion of heparin and HS with a cocktail of heparin lyases I-II-III (Grampian Enzymes, Aberdeen, UK), was carried out at $37^{\circ} \mathrm{C}$ for $48 \mathrm{~h}$, then stopped by boiling for $10 \mathrm{~min}$ followed by $0.2 \mu \mathrm{m}$ filtration. Products were recovered by $3 \mathrm{kDa}$ ultrafiltration, desalted and lyophilized. $100 \mu \mathrm{L}$ sample solution was prepared for HPLC-MS analysis on a LC system coupled with an ESI-Q-TOF 
mass-spectrometer (micrOTOFq, Bruker Daltonics, Bremen, Germany). The chromatographic separation was performed using a Kinetex C18 analytical column $(100 \times 2.1 \mathrm{~mm}, 2.6 \mu \mathrm{m}$ particle size, Phenomenex, Torrance, CA, USA) with Security Guard Cartridges Gemini C18 $(4 \times 2.0 \mathrm{~mm}$, Phenomenex). A binary solvent system was used for gradient elution at $0.1 \mathrm{ml} / \mathrm{min}$ of solvent $\mathrm{A}$ (10 mM DBA, $10 \mathrm{mM} \mathrm{CH}_{3} \mathrm{COOH}$ in water) and solvent $\mathrm{B}\left(10 \mathrm{mM}\right.$ DBA and $10 \mathrm{mM} \mathrm{CH}_{3} \mathrm{COOH}$ in methanol): t $0^{\prime} 10 \% \mathrm{~B}, \mathrm{t} 35^{\prime} 40 \% \mathrm{~B}, \mathrm{t} 85^{\prime} 50 \% \mathrm{~B}, \mathrm{t} 88^{\prime} 90 \% \mathrm{~B}$, t $95^{\prime} 10 \% \mathrm{~B}$. Disaccharide standards were purchased from Iduron, Manchester, UK. Data were processed by the DataAnalysis software (HyStar Compass, version 3.2, Bruker Daltonics).

\subsection{Evaluation of Cytokines/Chemokines}

Cytokines/chemokines and growth factors were measured by Bioplex in the lung homogenates, according to the manufacturer's instructions [11].

\subsection{Evaluation of P. aeruginosa Biofilm Formation}

Biofilm production was evaluated using the method of staining with crystal violet, as previously described [44]. AA43 was grown for $24 \mathrm{~h}$ at $37{ }^{\circ} \mathrm{C}$ either in the absence or presence of different concentrations of $\mathrm{C}_{\mathrm{gs} 20}$ and $\mathrm{C} 23(10 \mu \mathrm{g} / \mathrm{mL}, 1 \mu \mathrm{g} / \mathrm{mL}$ and $0.1 \mu \mathrm{g} / \mathrm{mL})$. Biofilm biomass was quantified by staining with crystal violet and absorbance measurements at $\mathrm{OD}_{600}$. Absorbance of planktonic bacteria in the culture medium was measured at $\mathrm{OD}_{600}$. Results are expressed as the ratio between biofilm absorbance and planktonic bacteria absorbance normalized on the value obtained for AA43 treated with the vehicle. Further details can be found in the Supplementary Materials.

\subsection{Statistics}

Statistics were performed with GraphPad Prism. Data analysis was performed using one-way ANOVA followed by Dunnett's analysis to correct for multiple comparisons for CFU counts, cellular counts and cytokine/chemokines quantification. Incidences of chronic colonization were compared using Fisher exact test. Two-way ANOVA with Bonferroni's Multiple Comparison test was used to compare changes in body weight. $p<0.05$ was considered significant.

\section{Conclusions}

In conclusion, our study shows that chronic P. aeruginosa lung infection increased HS levels in the murine lungs, and that interfering with this phenomenon dampened the inflammatory response. We indeed demonstrated that synthesized HS competitors decreased leukocyte recruitment and cytokine/chemokine production both during acute P. aeruginosa infection, and during the development and the course of chronic lung infection in mice. In addition, these compounds reduced $P$. aeruginosa infection in the agar-beads mouse model. Overall, these data support further evaluation of HS competitors as novel therapeutic molecules to counteract excessive inflammation induced by P. aeruginosa pulmonary infections in patients affected by chronic respiratory diseases.

Supplementary Materials: Supplementary materials can be found at www.mdpi.com/1422-0067/19/1/207/s1.

Acknowledgments: The authors thank Burkhard Tümmler (Medizinische Hochschule Hannover, Germany) for supplying P. aeruginosa clinical isolates and Francesco Viviani for his technical support. This study was supported to Cristina Cigana by Italian Cystic Fibrosis Research Foundation (FFC\#14/2013 and 18/2016), with the contribution of the Delegazioni FFC di Milano, Palermo, Vittoria, Ragusa e Siracusa, Catania Mascalucia, Messina, and Gruppo di Sostegno FFC di Tremestieri. Barbara Sipione and Noemi Veraldi had been supported by fellowships of the Italian Cystic Fibrosis Research Foundation.

Author Contributions: Cristina Cigana, Nicola Ivan Lorè and Annamaria Naggi conceived and designed the experiments; Cristina Cigana, Nicola Ivan Lorè, Noemi Veraldi, Camilla Riva, Barbara Sipione, Ida De Fino, Lorenza Spagnuolo, Elisa Calzi and Medede Melessike performed the experiments; Cristina Cigana, Nicola Ivan Lorè, Noemi Veraldi, Camilla Riva and Barbara Sipione analyzed the data; Cristina Cigana, Nicola Ivan Lorè, Noemi Veraldi and Annamaria Naggi interpreted the experiments results; Cristina Cigana and Noemi Veraldi prepared the figures; Cristina Cigana and Alessandra Bragonzi contributed 
reagents/materials/analysis tools; Cristina Cigana and Nicola Ivan Lorè wrote the manuscript. All authors reviewed the manuscript.

Conflicts of Interest: The authors declare no conflict of interest. The founding sponsor had no role in the design of the study; in the collection, analyses, or interpretation of data; in the writing of the manuscript, and in the decision to publish the results.

\section{References}

1. Hassett, D.J.; Borchers, M.T.; Panos, R.J. Chronic obstructive pulmonary disease (COPD): Evaluation from clinical, immunological and bacterial pathogenesis perspectives. J. Microbiol. 2014, 52, 211-226. [CrossRef] [PubMed]

2. Cohen, T.S.; Prince, A. Cystic fibrosis: A mucosal immunodeficiency syndrome. Nat. Med. 2012, 18, 509-519. [CrossRef] [PubMed]

3. Suzuki, A.; Kondoh, Y. The clinical impact of major comorbidities on idiopathic pulmonary fibrosis. Respir. Investig. 2017, 55, 94-103. [CrossRef] [PubMed]

4. Reeves, E.P.; Bergin, D.A.; Murray, M.A.; McElvaney, N.G. The involvement of glycosaminoglycans in airway disease associated with cystic fibrosis. Sci. World J. 2011, 11, 959-971. [CrossRef] [PubMed]

5. Proudfoot, A.E.; Handel, T.M.; Johnson, Z.; Lau, E.K.; LiWang, P.; Clark-Lewis, I.; Borlat, F.; Wells, T.N.; Kosco-Vilbois, M.H. Glycosaminoglycan binding and oligomerization are essential for the in vivo activity of certain chemokines. Proc. Natl. Acad. Sci. USA 2003, 100, 1885-1890. [CrossRef] [PubMed]

6. Sadir, R.; Forest, E.; Lortat-Jacob, H. The heparan sulfate binding sequence of interferon-gamma increased the on rate of the interferon-gamma-interferon-gamma receptor complex formation. J. Biol. Chem. 1998, 273, 10919-10925. [CrossRef] [PubMed]

7. Solic, N.; Wilson, J.; Wilson, S.J.; Shute, J.K. Endothelial activation and increased heparan sulfate expression in cystic fibrosis. Am. J. Respir. Crit. Care Med. 2005, 172, 892-898. [CrossRef] [PubMed]

8. Papakonstantinou, E.; Klagas, I.; Roth, M.; Tamm, M.; Stolz, D. Acute Exacerbations of COPD Are Associated With Increased Expression of Heparan Sulfate and Chondroitin Sulfate in BAL. Chest 2016, 149, 685-695. [CrossRef] [PubMed]

9. Westergren-Thorsson, G.; Hedstrom, U.; Nybom, A.; Tykesson, E.; Ahrman, E.; Hornfelt, M.; Maccarana, M.; van Kuppevelt, T.H.; Dellgren, G.; Wildt, M.; et al. Increased deposition of glycosaminoglycans and altered structure of heparan sulfate in idiopathic pulmonary fibrosis. Int. J. Biochem. Cell Biol. 2017, 83, 27-38. [CrossRef] [PubMed]

10. Veraldi, N.; Hughes, A.J.; Rudd, T.R.; Thomas, H.B.; Edwards, S.W.; Hadfield, L.; Skidmore, M.A.; Siligardi, G.; Cosentino, C.; Shute, J.K.; et al. Heparin derivatives for the targeting of multiple activities in the inflammatory response. Carbohydr. Polym. 2015, 117, 400-407. [CrossRef] [PubMed]

11. Cigana, C.; Lore, N.I.; Riva, C.; De Fino, I.; Spagnuolo, L.; Sipione, B.; Rossi, G.; Nonis, A.; Cabrini, G.; Bragonzi, A. Tracking the immunopathological response to Pseudomonas aeruginosa during respiratory infections. Sci. Rep. 2016, 6, 21465. [CrossRef] [PubMed]

12. Linhardt, R.J.; Turnbull, J.E.; Wang, H.M.; Loganathan, D.; Gallagher, J.T. Examination of the substrate specificity of heparin and heparan sulfate lyases. Biochemistry 1990, 29, 2611-2617. [CrossRef] [PubMed]

13. Prabhakar, V.; Capila, I.; Raman, R.; Srinivasan, A.; Bosques, C.J.; Pojasek, K.; Wrick, M.A.; Sasisekharan, R. The catalytic machinery of chondroitinase ABC I utilizes a calcium coordination strategy to optimally process dermatan sulfate. Biochemistry 2006, 45, 11130-11139. [CrossRef] [PubMed]

14. Yamada, S.; Yoshida, K.; Sugiura, M.; Sugahara, K.; Khoo, K.H.; Morris, H.R.; Dell, A. Structural studies on the bacterial lyase-resistant tetrasaccharides derived from the antithrombin III-binding site of porcine intestinal heparin. J. Biol. Chem. 1993, 268, 4780-4787. [PubMed]

15. Casu, B.; Guerrini, M.; Guglieri, S.; Naggi, A.; Perez, M.; Torri, G.; Cassinelli, G.; Ribatti, D.; Carminati, P.; Giannini, G.; Penco, S.; et al. Undersulfated and glycol-split heparins endowed with antiangiogenic activity. J. Med. Chem. 2004, 47, 838-848. [CrossRef] [PubMed]

16. Spencer, J.L.; Stone, P.J.; Nugent, M.A. New insights into the inhibition of human neutrophil elastase by heparin. Biochemistry 2006, 45, 9104-9120. [CrossRef] [PubMed]

17. Spillmann, D.; Witt, D.; Lindahl, U. Defining the interleukin-8-binding domain of heparan sulfate. J. Biol. Chem. 1998, 273, 15487-15493. [CrossRef] [PubMed] 
18. Casu, B.; Naggi, A.; Torri, G. Heparin-derived heparan sulfate mimics to modulate heparan sulfate-protein interaction in inflammation and cancer. Matrix Biol. 2010, 29, 442-452. [CrossRef] [PubMed]

19. Lore, N.I.; Cigana, C.; De Fino, I.; Riva, C.; Juhas, M.; Schwager, S.; Eberl, L.; Bragonzi, A. Cystic fibrosis-niche adaptation of Pseudomonas aeruginosa reduces virulence in multiple infection hosts. PLoS ONE 2012, 7, e35648. [CrossRef] [PubMed]

20. Lore, N.I.; Cigana, C.; Riva, C.; De Fino, I.; Nonis, A.; Spagnuolo, L.; Sipione, B.; Cariani, L.; Girelli, D.; Rossi, G.; et al. IL-17A impairs host tolerance during airway chronic infection by Pseudomonas aeruginosa. Sci. Rep. 2016, 6, 25937. [CrossRef] [PubMed]

21. Chan, S.C.; Shum, D.K.; Ip, M.S. Sputum sol neutrophil elastase activity in bronchiectasis: Differential modulation by syndecan-1. Am. J. Respir. Crit. Care Med. 2003, 168, 192-198. [CrossRef] [PubMed]

22. Spagnuolo, L.; De Simone, M.; Lore, N.I.; De Fino, I.; Basso, V.; Mondino, A.; Cigana, C.; Bragonzi, A. The host genetic background defines diverse immune-reactivity and susceptibility to chronic Pseudomonas aeruginosa respiratory infection. Sci. Rep. 2016, 6, 36924. [CrossRef] [PubMed]

23. De Simone, M.; Spagnuolo, L.; Lore, N.I.; Rossi, G.; Cigana, C.; De Fino, I.; Iraqi, F.A.; Bragonzi, A. Host genetic background influences the response to the opportunistic Pseudomonas aeruginosa infection altering cell-mediated immunity and bacterial replication. PLoS ONE 2014, 9, e106873. [CrossRef] [PubMed]

24. Lore, N.I.; Iraqi, F.A.; Bragonzi, A. Host genetic diversity influences the severity of Pseudomonas aeruginosa pneumonia in the Collaborative Cross mice. BMC Genet. 2015, 16, 106. [CrossRef] [PubMed]

25. Papakonstantinou, E.; Karakiulakis, G. The 'sweet' and 'bitter' involvement of glycosaminoglycans in lung diseases: Pharmacotherapeutic relevance. Br. J. Pharmacol. 2009, 157, 1111-1127. [CrossRef] [PubMed]

26. Polverino, E.; Rosales-Mayor, E.; Dale, G.E.; Dembowsky, K.; Torres, A. The Role of Neutrophil Elastase Inhibitors in Lung Diseases. Chest 2017, 152, 249-262. [CrossRef] [PubMed]

27. Walsh, R.L.; Dillon, T.J.; Scicchitano, R.; McLennan, G. Heparin and heparan sulphate are inhibitors of human leucocyte elastase. Clin. Sci. 1991, 81, 341-346. [CrossRef] [PubMed]

28. Doring, G.; Bragonzi, A.; Paroni, M.; Akturk, F.F.; Cigana, C.; Schmidt, A.; Gilpin, D.; Heyder, S.; Born, T.; Smaczny, C.; et al. BIIL 284 reduces neutrophil numbers but increases $P$. aeruginosa bacteremia and inflammation in mouse lungs. J. Cyst. Fibros. 2014, 13, 156-163. [CrossRef] [PubMed]

29. Yonker, L.M.; Cigana, C.; Hurley, B.P.; Bragonzi, A. Host-pathogen interplay in the respiratory environment of cystic fibrosis. J. Cyst. Fibros. 2015, 14, 431-439. [CrossRef] [PubMed]

30. Lore, N.I.; Bragonzi, A.; Cigana, C. The IL-17A/IL-17RA axis in pulmonary defence and immunopathology. Cytokine Growth Factor Rev. 2016, 30, 19-27. [CrossRef] [PubMed]

31. Guragain, M.; King, M.M.; Williamson, K.S.; Perez-Osorio, A.C.; Akiyama, T.; Khanam, S.; Patrauchan, M.A.; Franklin, M.J. The Pseudomonas aeruginosa PAO1 Two-Component Regulator CarSR Regulates Calcium Homeostasis and Calcium-Induced Virulence Factor Production through Its Regulatory Targets CarO and CarP. J. Bacteriol. 2016, 198, 951-963. [CrossRef] [PubMed]

32. Plotkowski, M.C.; Costa, A.O.; Morandi, V.; Barbosa, H.S.; Nader, H.B.; de Bentzmann, S.; Puchelle, E. Role of heparan sulphate proteoglycans as potential receptors for non-piliated Pseudomonas aeruginosa adherence to non-polarised airway epithelial cells. J. Med. Microbiol. 2001, 50, 183-190. [CrossRef] [PubMed]

33. Bucior, I.; Pielage, J.F.; Engel, J.N. Pseudomonas aeruginosa pili and flagella mediate distinct binding and signaling events at the apical and basolateral surface of airway epithelium. PLoS Pathog. 2012, 8, e1002616. [CrossRef] [PubMed]

34. Cigana, C.; Curcuru, L.; Leone, M.R.; Ierano, T.; Lore, N.I.; Bianconi, I.; Silipo, A.; Cozzolino, F.; Lanzetta, R.; Molinaro, A.; et al. Pseudomonas aeruginosa exploits lipid A and muropeptides modification as a strategy to lower innate immunity during cystic fibrosis lung infection. PLoS ONE 2009, 4, e8439. [CrossRef] [PubMed]

35. Cigana, C.; Lore, N.I.; Bernardini, M.L.; Bragonzi, A. Dampening Host Sensing and Avoiding Recognition in Pseudomonas aeruginosa Pneumonia. J. Biomed. Biotechnol. 2011, 2011, 852513. [CrossRef] [PubMed]

36. Bragonzi, A.; Paroni, M.; Nonis, A.; Cramer, N.; Montanari, S.; Rejman, J.; Di Serio, C.; Doring, G.; Tummler, B. Pseudomonas aeruginosa microevolution during cystic fibrosis lung infection establishes clones with adapted virulence. Am. J. Respir. Crit. Care Med. 2009, 180, 138-145. [CrossRef] [PubMed]

37. Naggi, A.; Casu, B.; Perez, M.; Torri, G.; Cassinelli, G.; Penco, S.; Pisano, C.; Giannini, G.; Ishai-Michaeli, R.; Vlodavsky, I. Modulation of the heparanase-inhibiting activity of heparin through selective desulfation, graded N-acetylation, and glycol splitting. J. Biol. Chem. 2005, 280, 12103-12113. [CrossRef] [PubMed] 
38. Bertini, S.; Bisio, A.; Torri, G.; Bensi, D.; Terbojevich, M. Molecular weight determination of heparin and dermatan sulfate by size exclusion chromatography with a triple detector array. Biomacromolecules 2005, 6, 168-173. [CrossRef] [PubMed]

39. Kukavica-Ibrulj, I.; Facchini, M.; Cigana, C.; Levesque, R.C.; Bragonzi, A. Assessing Pseudomonas aeruginosa virulence and the host response using murine models of acute and chronic lung infection. Methods Mol. Biol. 2014, 1149, 757-771. [PubMed]

40. Yang, Y.; MacLeod, V.; Dai, Y.; Khotskaya-Sample, Y.; Shriver, Z.; Venkataraman, G.; Sasisekharan, R.; Naggi, A.; Torri, G.; Casu, B.; et al. The syndecan-1 heparan sulfate proteoglycan is a viable target for myeloma therapy. Blood 2007, 110, 2041-2048. [CrossRef] [PubMed]

41. Poli, M.; Asperti, M.; Naggi, A.; Campostrini, N.; Girelli, D.; Corbella, M.; Benzi, M.; Besson-Fournier, C.; Coppin, H.; Maccarinelli, F.; et al. Glycol-split nonanticoagulant heparins are inhibitors of hepcidin expression in vitro and in vivo. Blood 2014, 123, 1564-1573. [CrossRef] [PubMed]

42. Cassinelli, G.; Lanzi, C.; Tortoreto, M.; Cominetti, D.; Petrangolini, G.; Favini, E.; Zaffaroni, N.; Pisano, C.; Penco, S.; Vlodavsky, I.; et al. Antitumor efficacy of the heparanase inhibitor SST0001 alone and in combination with antiangiogenic agents in the treatment of human pediatric sarcoma models. Biochem. Pharmacol. 2013, 85, 1424-1432. [CrossRef] [PubMed]

43. Bragonzi, A.; Worlitzsch, D.; Pier, G.B.; Timpert, P.; Ulrich, M.; Hentzer, M.; Andersen, J.B.; Givskov, M.; Conese, M.; Doring, G. Nonmucoid Pseudomonas aeruginosa expresses alginate in the lungs of patients with cystic fibrosis and in a mouse model. J. Infect. Dis. 2005, 192, 410-419. [CrossRef] [PubMed]

44. Baldan, R.; Cigana, C.; Testa, F.; Bianconi, I.; De Simone, M.; Pellin, D.; Di Serio, C.; Bragonzi, A.; Cirillo, D.M. Adaptation of Pseudomonas aeruginosa in Cystic Fibrosis airways influences virulence of Staphylococcus aureus in vitro and murine models of co-infection. PLOS ONE 2014, 9, e89614. [CrossRef] [PubMed]

(C) 2018 by the authors. Licensee MDPI, Basel, Switzerland. This article is an open access article distributed under the terms and conditions of the Creative Commons Attribution (CC BY) license (http://creativecommons.org/licenses/by/4.0/). 